\title{
CONCENTRAÇÃO DE PROPRIEDADE, GOVERNANÇA CORPORATIVA E ESTRUTURA DE CAPITAL NO SEGMENTO DE ENERGIA ELÉTRICA DA B3 ${ }^{1}$
}

\section{CONCENTRATION OF PROPERTY, CORPORATE GOVERNANCE AND CAPITAL STRUC- TURE IN THE B3 ELECTRICITY SEGMENT}

\author{
Flávio Ribeiro \\ Doutor em Contabilidade pela Universidade Federal do Paraná (UFPR) \\ Universidade Estadual do Centro Oeste (UNICENTRO) \\ flavioribeiro@unicentro.br \\ Mauricio João Atamanczuk \\ Doutor em Administração pela Universidade Positivo (UP) \\ Universidade Estadual do Centro Oeste (UNICENTRO) \\ mauricioata@yahoo.com.br

\section{Willson Gerigk} \\ Doutor em Políticas Públicas pela Universidade Federal do Paraná (UFPR) \\ Universidade Estadual do Centro Oeste (UNICENTRO) \\ wgerigk@unicentro.br

\section{Luan Felipe Biscaia} \\ Graduado em Ciências Contábeis pela Universidade Estadual do Centro-Oeste (UNICENTRO) \\ Universidade Estadual do Centro Oeste (UNICENTRO) \\ luan biscaia@hotmail.com
}

\section{RESUMO}

Objetivo: Esta pesquisa buscou identificar a influência exercida pela concentração de propriedade e pelo nível de governança corporativa sobre o endividamento das empresas listadas no segmento de energia elétrica da B3, nos anos de 2012 a 2017.

Fundamento: $\mathrm{O}$ estudo fundamenta-se nas teorias da estrutura de capital, da concentração de propriedade e de governança corporativa aplicadas às companhias de capital abertas do segmento de energia elétrica brasileiro.

Método: Foram analisadas 58 empresas pertencentes ao setor de energia elétrica da bolsa de valores brasileira. A coleta de dados foi feita junto aos demonstrativos financeiros disponibilizados no site da B3. As análises envolveram as variáveis explicadas: endividamento geral e a composição do endividamento. Como variáveis explicativas utilizou-se: a concentração de propriedade; a

\footnotetext{
${ }^{1}$ Artigo recebido em: 11/06/2020. Revisado por pares em: 14/05/2021. Reformulado em: 17/03/2021. Recomendado para publicação: 18/05/2021 por Marco Aurélio dos Santos (Editor Adjunto). Publicado em: 31/08/2021. Organização responsável pelo periódico: UFPB
} 
governança corporativa; o tamanho da empresa; o retorno sobre o patrimônio líquido e a alavancagem financeira. A técnica estatística usada foi de dados em painel.

Resultados: Os resultados indicaram que tanto a Governança Corporativa quanto a Concentração de Propriedade se mostraram influentes em relação ao Endividamento Geral e não apresentaram significância estatística para com a Composição do Endividamento junto às empresas do segmento de energia elétrica da B3.

Contribuições: $O$ presente estudo se propõe a contribuir com a discussão que envolve os efeitos da concentração de propriedade e da governança corporativa em relação à estrutura de capital das companhias abertas brasileiras do setor de energia elétrica, segmento este que se caracteriza como altamente regulamentado pelo Governo Federal e conta com grandes companhias administradas por entes públicos estaduais.

Palavras-chave: Estrutura de capital. Concentração de propriedade. Governança corporativa. Companhias de energia elétrica.

\section{ABSTRACT}

Objective: This research sought to identify the influence exerted by the concentration of ownership and the level of corporate governance on the indebtedness of companies listed in b3's electricity segment, from 2012 to 2017.

Foundation: The study is based on theories of capital structure, concentration of ownership and corporate governance applied to publicly traded companies in the Brazilian electric energy segment.

Method: Fifty-eight companies belonging to the electricity sector of the Brazilian stock exchange were analyzed. Data collection was done with the financial statements made available on b3's website. The analyses involved the variables explained: general indebtedness and the composition of indebtedness. And as explanatory the concentration of property; corporate governance; company size; return on equity and financial leverage. The statistical technique used was panel data.

Results: The results indicated that both Corporate Governance and The Property Concentration were influential in relation to General Indebtedness and showed no statistical significance to the Composition of Indebtedness, together with the companies of the B3's electricity segment.

Contributions: This study proposes to contribute to the discussion that involves the effects of the concentration of ownership of corporate governance in relation to the capital structure of public companies in the electricity sector, this segment, which is dialed as highly regulated by the Federal Government and it has large companies managed by state public entities.

Keywords: Capital Structure. Property Concentration. Corporate Governance. Electric Power Companies.

\section{INTRODUÇÃO}

O setor de atuação com o maior número de empresas listadas na B3 é o de energia elétrica (B3, 2018). Este tem importância pelo desenvolvimento econômico e estrutural do país, além de contar com elevada capacidade de gerar receita bruta (ANEEL, 2018). Tolmasquim, Guerreiro e Gorini (2007) estimam que entre os anos de 2005 a 2030 o consumo de energia elétrica no Brasil crescerá em $100 \%$. Com isso, espera-se que a continuidade das empresas que integram esse setor revele-se duradoura, e que tal crescimento não seja prejudicial aos investidores e aos consumidores dos serviços prestados. 
O setor brasileiro de energia elétrica possui 60 empresas. A receita bruta desse segmento, segundo dados da ANEEL, ultrapassou, no ano de 2017, R\$ 130 bilhões. A representatividade econômica e a diversidade de concentração de capital, segundo Sant'ana, Medeiro, Silva, Menezes e Chain (2016), contribuem para que haja um maior comprometimento com os resultados a serem obtidos pelas empresas de energia elétrica.

Em economias emergentes, segundo Okimura, Silveira e Rocha (2007), a concentração de propriedade é mais acentuada. No Brasil, a redução na concentração de propriedade em empresas é um movimento do mercado em razão das práticas de governança corporativa, principalmente pelo incentivo da bolsa de valores B3, que criou níveis de governança corporativa, que visam regulamentar e diminuir a disparidade informacional, além de proteger os direitos dos acionistas.

A governança corporativa e a concentração de propriedade estão diretamente relacionadas. A concentração de propriedade das empresas é determinada pela porcentagem de propriedade do acionista majoritário. Esta estrutura exerce influência sobre as práticas de governança corporativa, de modo que, empresas com elevada concentração de propriedade tendem a buscar um sistema de governança que privilegie essa composição acionária (Sant'ana, Medeiros, Silva, Menezes \& Chain, 2016). Empresas que apresentam estrutura de capital de terceiros superior ao capital próprio podem ser menos afetadas por esses aspectos (Pohlmann, Aguiar, Bertolucci \& Martins, 2004).

O endividamento pode levar a empresa a modificar ou alterar seus padrões de governança corporativa devido à pressão exercida por credores, com a finalidade de reduzir o risco de não obterem retorno de seus investimentos (Klapper \& Love, 2004; Brandão, Assunção, Ponte \& Rebouças, 2013; Brandão \& Crisóstomo, 2015). Empresas que seguem um padrão de governança corporativa, em geral, registram melhores resultados financeiros (Silveira, 2002). Okimura (2003) acrescenta que há influência da concentração de propriedade sobre os resultados financeiros das companhias.

Estudos empíricos explicam que estes elementos - concentração de propriedade e governança corporativa - podem exercer influência sobre a estrutura de capital das empresas (Crisóstomo \& Pinheiro, 2015; Mendonça, Martins \& Terra, 2019). Como suporte teórico para explicação deste comportamento destacam-se as seguintes teorias: Trade-off, Pecking Order, Agência e Market Timing (Pinheiro, Vasconcelos, De Luca, \& Crisóstomo, 2017). Desta forma, a presente pesquisa tem por finalidade verificar esta influência, sendo norteada pelo seguinte problema de pesquisa: A concentração de propriedade e o nível de governança corporativa exerceram influência sobre o endividamento das empresas listadas no segmento de energia elétrica da B3?

Considerando a importância do setor energia elétrica no mercado brasileiro, o objetivo do estudo é analisar se o endividamento contabilizado pelas companhias participantes deste da B3, entre os anos de 2012 a 2017, possui relação com os níveis de concentração de propriedade e de governança corporativa.

Além desta introdução, a segunda seção aborda o referencial teórico. Na sequência, a metodologia da pesquisa é explicitada. Os resultados são descritos na quarta seção e em seguida apresentam-se as considerações finais.

\section{REFERENCIAL TEÓRICO}

O referencial teórico apresenta conceitos relacionadas à estrutura de capital, concentração de propriedade e governança corporativa, necessários ao desenvolvimento do estudo.

\subsection{Estrutura de Capital}

Uma das áreas mais complexas da tomada de decisões dentro de uma empresa é a estrutura de capital, devido à sua interação com as demais variáveis financeiras. A eficaz gestão da estrutura de capital, considerando as diferentes formas de utilização do endividamento dentro das 
atividades da empresa e a relação entre o capital próprio e de terceiros são essenciais para o desenvolvimento de uma organização (Ortiz, Pilan \& Carvalho, 2008).

A estrutura de capital de uma empresa pode ser definida pela proporção entre as fontes de capital de terceiros e os recursos próprios que financiam os investimentos totais (Ross, Westerfield, Jaffe \& Lamb, 2015). Para Gomes e Pereira (2014) a estrutura de capital define-se pela soma dos capitais exigíveis que financiam a(s) atividade(s) da empresa (Mazzioni, Prigol, Moura \& Klann, 2015).

Diferentes teorias procuram explicar o modo como as empresas determinam sua estrutura de capital. Modigliani e Miller (1958), considerando o mercado de capitais perfeito, teorizaram que a estrutura de capital torna-se irrelevante na determinação do valor da empresa (Proposição I). Todavia, em razão da existência de imperfeições no mercado quanto aos impostos sobre os lucros, os autores reconheceram que a estrutura de capital pode apresentar divergência do ponto de vista do valor das empresas (Modigliani \& Miller, 1963).

A partir dos estudos de Modigliani e Miller, outras teorias foram criadas visando abordar as imperfeições do mercado, sob diferentes aspectos. As teorias que se destacam na literatura são: Trade-off, Pecking Order, Agência e Market Timing (Pinheiro et al., 2017).

A teoria Trade-off, conforme Myers (1983), visa a maximização do uso do endividamento externo para financiar os investimentos. Assim, a estrutura de capital ótima é resultado da combinação do capital próprio e capital de terceiros.

Na teoria do Pecking Order, Myers (1983) indica que os investimentos deveriam seguir a seguinte ordem de financiamento: capital próprio, endividamento de longo prazo e endividamento de curto prazo. Assim, as empresas com alta lucratividade deveriam ser menos endividadas e as empresas com maior grau de endividamento menos lucrativas. Porém, empresas mais endividadas tendem a fornecer maior vantagem em relação ao retorno sobre o patrimônio líquido, visto que a alavancagem financeira aumenta a rentabilidade do capital próprio.

Nakamura et al. (2007) constataram, em seu estudo, com uma amostra de 91 empresas brasileiras durante o período de 1999 a 2003, que a dívida externa é fortemente preferida em relação ao patrimônio líquido como forma de financiamento. Assim, o tamanho das empresas e o crescimento de vendas teriam uma relação positiva com o endividamento.

Na ótica da teoria da Agência, a dívida tem o papel de reduzir os custos de monitoramento na relação entre o Principal e o Agente. Conforme Jensen (1986), o endividamento da empresa proporciona um menor fluxo de caixa livre, reduzindo, assim, os gastos discricionários do agente.

Por último, de acordo com Baker e Wuegler (2002), a teoria Market Timing defende a existência de práticas oportunistas na emissão de ações quando o mercado se apresenta favorável às vendas, e que a recompra de ações, por parte da empresa, deve ocorrer em momentos de preços baixos. Essa prática busca se beneficiar da flutuação temporária do valor das ações, a fim de minimizar o custo de capital próprio.

Para Perobelli e Famá (2003), a estrutura de capital exerce influência sobre diversos fatores financeiros, tais como: tamanho da empresa, grau de crescimento, estrutura dos ativos, lucratividade e volatilidade dos resultados operacionais. O tamanho, a rentabilidade e a tangibilidade dos ativos são considerados como determinantes da estrutura de capital nas empresas (Ortiz et al., 2008).

Bastos e Nakamura (2009) indicaram, em pesquisa com uma amostra de 297 empresas, de diversos setores, pertencentes ao Brasil, México e Chile, no período entre 2001 e 2006, que fatores específicos da firma, como liquidez corrente, rentabilidade, market to book value e tamanho apresentaram os resultados mais significantes para a estrutura de capital das empresas dos três países. 
Todavia, o estudo de Demsetz e Lehn (1985) argumenta que a estrutura de propriedade corporativa apresentou variação sistemática consistente com a maximização de valor, uma vez que não foi encontrada relação significativa entre a concentração de propriedade e as taxas de lucro contábil das empresas.

\subsection{Estrutura de Capital e Concentração de Propriedade}

De acordo com Crisóstomo e Pinheiro (2015) a concentração de propriedade pode contribuir para o acesso ao financiamento por algumas razões: o recurso ao uso de dívida devido à insuficiência de fluxo de caixa para financiar as oportunidades de crescimento; grandes acionistas evitam a emissão de ações por resistência à perda de poder; a dificuldade de emissão de ações por empresas com propriedade altamente concentrada; ou ainda, a maximização do benefício tributário da dívida.

O primeiro estudo que abordou sobre a concentração de propriedade e a relação entre outras variáveis das empresas foi feita por Adam Smith em 1776. O estudo abordou a relação entre o custo que poderia incorrer sobre as empresas em que o administrador não é detentor do capital, ou seja, como o administrador gerencia o capital a seu dispor (Sant'ana et al., 2016).

Segundo Valadares (1998), a concentração de propriedade pode ser dividida em: i) dispersa, em que a propriedade das ações é pulverizada e há um grande número de acionistas; e ii) concentrada, em que há poucos acionistas detendo grande quantidade de ações, existindo, ainda, o acionista controlador, que detém o controle da empresa.

Certas relações entre a concentração de propriedade e a gestão da empresa podem gerar problemas, considerando que um gestor tome decisões que priorizem seu bem-estar no lugar dos interesses dos investidores (Sant'ana et al., 2016).

Silveira (2004) identificou que a concentração de propriedade influencia a qualidade da governança corporativa. O estudo revelou que há uma relação negativa entre o direito ao voto do acionista majoritário e a qualidade da governança corporativa. Assim, administradores com maior capacidade intelectual, geralmente em empresas com estrutura acionária pulverizada, possuem melhor capacidade de gerir eficientemente a organização.

Certas relações entre a concentração de propriedade e a gestão da empresa podem gerar problemas, considerando que o acionista controlador pode usar de artifícios que o favoreçam, e que não necessariamente priorizem os interesses e necessidades da empresa e/ou dos acionistas minoritários (Sant'ana et al., 2016). Os acionistas controladores podem se utilizar das finanças da empresa de várias formas, como: pagamento de salários excessivos a si próprios, a autonomeação em cargos executivos privilegiados e posições no conselho para si próprios ou para familiares e/ou parentes, mesmo esses não sendo qualificados para tanto. Além disso, podem, também, pagar (ou receber) preços inflacionados (ou deflacionados) para empresas pertencentes a eles mesmos, entre outros fatores (Okimura, 2003).

A concentração de propriedade pode trazer benefícios e prejuízos para a empresa. Por exemplo, grandes acionistas trazem melhores resultados para a empresa, entretanto afetam negativamente o preço das ações. Por outro lado, empresas com baixa concentração de propriedade podem atender mais aos interesses de seus investidores, valorização das ações, que por muitas vezes são contrárias às necessidades das empresas (Silveira, 2004).

De acordo com Crisóstomo e Pinheiro (2015) a concentração de propriedade favorece o endividamento da empresa. Ademais, constataram um efeito quadrático inverso da concentração de propriedade, o que indica que a concentração tem um efeito positivo até certo limite, a partir do qual o excesso de concentração acionária prejudica a capacidade de financiamento por meio do endividamento. Tais resultados sugerem que a concentração de propriedade promove $o$ alinhamento de interesses entre propriedade e gestão, reduzindo os conflitos de agência com 
reflexo positivo no acesso ao financiamento externo (Goergen \& Renneboog, 2001). Assim, formula-se a seguinte hipótese:

H1: A concentração de propriedade influencia positivamente a estrutura de capital das companhias do segmento de energia elétrica.

\subsection{Estrutura de Capital e Governança Corporativa}

A melhor qualidade da Governança Corporativa (GC) pode contribuir positivamente ao acesso ao endividamento (Liao, Mukherjee \& Wang, 2015). O mercado de capitais brasileiro tem incentivado as boas práticas de GC para que as companhias alcancem sucesso em um mercado que está cada vez mais competitivo (Monte, Rezende, Teixeira, \& Besarria, 2010). Assim, a GC surgiu para criar um conjunto eficiente de mecanismos e normas, tanto de incentivos quanto de monitoramentos, com o objetivo de assegurar aos investidores que seus interesses estão sendo defendidos pelos executivos dentro das organizações (Niyama, Campos, Gonçalves \& Campos, 2012).

Para Silva, Oliveira, Mendes e Araújo (2009) são diversos os fatores que impulsionam o desenvolvimento das práticas de GC no Brasil, destacando-se a globalização da economia, as privatizações, o mínimo poder de decisão atribuído aos acionistas minoritários pela Lei das Sociedades Anônimas e o movimento internacional de fusões e aquisições.

A GC, segundo Andrade e Rossetti (2004), tem quatro funções dentro de um conjunto de diversidades que buscam o equilíbrio empresarial. A primeira é a de Guardiã de Direitos, que busca a garantia dos direitos de todas as partes envolvidas na empresa. O Sistema de Relações tem por função efetivar a relação entre a administração, os conselhos e os acionistas. A Estrutura de Poder, a estrutura interna corporativa, visa maior rentabilidade e retorno aos acionistas. E o Sistema Normativo objetiva propiciar estabilidade aos investidores e rege as relações internas e externas da empresa.

Tais práticas de GC têm por objetivo gerar benefícios ao mercado acionário como um todo. Nardi e Nakao (2008) resumem esses benefícios em duas categorias: para os investidores e para as empresas. Para os investidos as boas práticas de GC trazem maior precisão para seus investimentos e à precificação das ações, traz clareza e melhora o processo de fiscalização sobre a diretoria, maior segurança e confiança quanto aos seus direitos societários, redução do risco e aumento de lucratividade. Para as empresas, melhoram a imagem institucional, aumentam a valorização das ações, reduzem o custo de capital e melhoram seu desempenho.

Silveira, Perobelli e Barros (2008) investigaram a influência da prática de governança corporativa na estrutura de capital nas empresas brasileiras. Os resultados revelaram significativa influência das práticas de governança sobre a alavancagem financeira, em particular daquelas relacionadas com a dimensão estrutura de propriedade, sugerindo que a governança corporativa pode ser determinante relevante da estrutura de capital.

Nessa mesma linha, em um estudo com 252 empresas brasileiras de capital aberto, no período de 2000 a 2013, Fonseca, Silveira e Hiratuka (2016) observaram relação positiva entre a GC e o endividamento total, oneroso e de longo prazo, constatando-se que a governança facilita o acesso ao financiamento por meio do capital de terceiros. Resultados similares foram constatados por Mapurunga, Ponte e Oliveira (2015), que analisando uma amostra de 554 empresas de capital aberto não financeiras registradas na CVM, na posição de 31/12/2011, observaram que as variáveis tamanho e endividamento mostraram-se associadas positivamente às boas práticas de governança corporativa.

Mendonça et al. (2019) investigaram em que medida os mecanismos de governança externos à firma afetam a alavancagem financeira de uma amostra de 7.490 empresas de 40 países. Os resultados sugerem que as empresas se alavancam de maneira coerente ao previsto pela Teoria 
da Pecking Order (POT). Quando a proteção é alta, as empresas tomam menos dívida. Os resultados mostraram-se robustos a diversas variações no modelo estudado e indicaram que, quando a proteção aos investidores externos é maior, as firmas tomam menos dívida, possivelmente com a finalidade de restringir o papel monitorador da dívida sobre a discricionariedade dos insiders.

Vieira, Velasquez, Losekann e Ceretta (2011) analisaram 84 empresas brasileiras classificadas nos níveis diferenciados de governança corporativa da B3 (Nivel 1, Nível 2 e Novo Mercado), no período de 2001 a 2006. Os resultados indicaram que as empresas que aderiram ao Nível 1, ao Nível 2 e aquelas que optaram pelo Novo Mercado adotaram as práticas de governança corporativa sugeridas pela bolsa, mas o índice de GC não influenciou o endividamento nas empresas pesquisadas.

Por outro lado, Pinheiro et al. (2017), investigando as empresas listadas na B3 no período de 2010 a 2014, constataram que a governança corporativa influenciou negativamente o endividamento subsidiado, confirmando-se no mercado brasileiro o que preceitua a Teoria Pecking Order. Perceptivelmente, a literatura sobre a relação entre a governança corporativa e a estrutura de capital é heterogênea e divergente. Assim, formula-se a seguinte hipótese:

H2: O nível de Governança Corporativa influencia negativamente a estrutura de capital das empresas do segmento de energia elétrica.

\section{METODOLOGIA}

A partir das características da investigação, a pesquisa enquadra-se como descritiva, documental, com abordagem quantitativa. O estudo analisa a relação entre a concentração de propriedade e as práticas de governança corporativa quanto à estrutura de capital das companhias do segmento de energia elétrica da B3.

A população da pesquisa é representada por 60 empresas listadas no segmento de energia elétrica da B3, considerando o recorte temporal entre os anos de 2012 e 2017. A amostra compreendeu 58 companhias, para as quais se pôde extrair todos os dados necessários para desenvolvimento da pesquisa.

Optou-se por iniciar o estudo no ano de 2012 devido à obrigatoriedade, no Brasil, de as companhias adequarem suas contabilidades às Normas Internacionais de Contabilidade (IFRS), a partir de 2010. Assim, a presente pesquisa assume que todos os efeitos de tal convergência teriam ocorrido antes de 2012, ou seja, todas as empresas estudadas adotariam o mesmo padrão contábil no encerramento do exercício financeiro de 2012.

A pesquisa documental foi empregada para classificar as empresas nos níveis de governança corporativa da B3, bem como para obter as informações quantitativas a partir dos demonstrativos financeiros e das notas explicativas divulgadas por estas. As variáveis utilizadas são apresentadas no Quadro 1. 


\begin{tabular}{|c|c|c|c|c|}
\hline \multirow{2}{*}{\multicolumn{2}{|c|}{ Variáveis }} & Ḿnis & Sim & Boforn̂ngi \\
\hline & & & & \\
\hline \multirow{2}{*}{ Dependentes } & $\begin{array}{c}\text { Endividamento } \\
\text { Geral }\end{array}$ & $\begin{array}{c}\text { Relação entre o Capital de Terceiros e o } \\
\text { Ativo Total }\end{array}$ & $--\mathrm{x--}$ & $--\mathrm{-}--$ \\
\hline & $\begin{array}{l}\text { Composição do } \\
\text { Endividamento }\end{array}$ & $\begin{array}{c}\text { Relação entre o Passivo Circulante e o } \\
\text { Capital de Terceiros }\end{array}$ & $--x--$ & $--\mathrm{x}--$ \\
\hline \multirow[b]{2}{*}{ Independentes } & $\begin{array}{l}\text { Concentração de } \\
\text { Propriedade }\end{array}$ & $\begin{array}{l}\text { Porcentual de ações ordinárias em posse } \\
\text { do maior acionista }\end{array}$ & $(+)$ & $\begin{array}{c}\text { Póvoa e } \\
\text { Nakamura } \\
(2015) \\
\end{array}$ \\
\hline & $\begin{array}{l}\text { Governança } \\
\text { Corporativa }\end{array}$ & $\begin{array}{l}\text { Variável categórica que receberá valor } \\
\text { “1” quando a empresa da amostra é } \\
\text { listada nos níveis diferenciados de GC } \\
\text { da B3 e “0” quando não. }\end{array}$ & $(-)$ & $\begin{array}{c}\text { Vieira et al. } \\
\text { (2011); } \\
\text { Mazzioni et al. } \\
\text { (2015); } \\
\text { Pinheiro et al. } \\
\text { (2017) }\end{array}$ \\
\hline \multirow{3}{*}{ Controles } & $\begin{array}{l}\text { Tamanho da } \\
\text { Empresa }\end{array}$ & Logaritmo natural do Ativo Total & $(+)$ & $\begin{array}{c}\text { Bastos e } \\
\text { Nakamura } \\
(2009)\end{array}$ \\
\hline & $\begin{array}{c}\text { Retorno sobre o } \\
\text { Patrimônio Líquido }\end{array}$ & $\begin{array}{c}\text { Relação entre o Resultado Líquido e o } \\
\text { Patrimônio Líquido }\end{array}$ & $(+)$ & $\begin{array}{c}\text { Nakamura et } \\
\text { al. (2007) }\end{array}$ \\
\hline & $\begin{array}{l}\text { Alavancagem } \\
\text { Financeira }\end{array}$ & Relação entre o ROE e o ROA & $(+)$ & $\begin{array}{l}\text { Perobelli e } \\
\text { Famá (2003) }\end{array}$ \\
\hline
\end{tabular}

Fonte: Elaborado pelos autores (2020).

Como variáveis dependentes, ou explicadas, utilizaram-se dois indicadores de endividamento: Endividamento Geral e Composição do Endividamento. A primeira variável avalia a relação entre o endividamento e o total de recursos da organização, e a segunda variável considera o prazo de quitação dos recursos tomado de terceiros.

As variáveis explicativas empregadas no estudo foram a concentração de propriedade, por meio do levantamento do percentual de ações ordinárias de posse do maior acionista; e o nível de governança corporativa, a partir das informações disponibilizadas pelas organizações. Estas foram selecionadas conforme os estudos de Póvoa e Nakamura (2015) e Mazzioni et al. (2015).

Para a aplicação dos testes estatísticos foram consideradas ainda três variáveis de controle: i) tamanho da empresa; ii) retorno sobre o PL; e iii) alavancagem; que podem impactar os resultados, e por essa razão foram controladas na pesquisa (Bastos \& Nakamura, 2009; Nakamura et al., 2007; Perobelli \& Famá, 2003).

Inicialmente analisaram-se as variáveis por meio de estatística descritiva, para compreender e evidenciar aspectos que possam tornar-se relevantes ou limitantes ao estudo. Após, para atender ao objetivo da pesquisa, empregou-se análise de dados em painel.

Segundo Fávero, Belfiore, Silva e Chan (2009), a análise de dados em painel combina a abordagem cross-sectional - que estuda o comportamento das variáveis para observações da amostra com o tempo fixo: dia, mês ou ano - e a de séries temporais - que permite analisar a evolução das variáveis observadas ao longo de determinado período.

Os métodos utilizados nas análises de dados em painel são: POLS (Pooled Ordinary Least Squared), efeitos fixos e efeitos aleatórios. Primeiro realiza-se o Teste de Chow para verificar se o modelo restrito (POLS) é mais indicado que o de efeitos fixos. Analisa-se a estatística do teste $\mathrm{F}$ da estimação com efeitos fixos. Se for significante a $5 \%$ (Prob<0,05), o modelo de efeitos fixos é melhor que o POLS. Depois, para escolher entre os métodos de efeitos fixos ou de efeitos aleatórios, o teste utilizado é o de Hausman. Se o resultado for significante a $5 \%$ (Prob< 0,05$)$, o método indicado é o de efeitos fixos, se não, os dois métodos são adequados, ou seja, suas estimativas são semelhantes. 
Neste caso, usa-se o método de efeitos aleatórios, por ser mais eficiente para as estimações (Fávero et al., 2009).

Os testes indicaram para a amostra em estudo a utilização do modelo de efeitos aleatórios, tanto para a variável dependente Endividamento Geral como para a Composição do Endividamento. Com isso, os modelos analisados seguem a formalização das Equações 1 e 2.
$Y($ Endividamento Geralit $)=\beta_{0 i t}+\beta_{1}($ Governança Corporativait $)+\beta_{2}($ Tamanho da Em- presait $)+\beta_{3}$ (Retorno sobre o Patrimônio Líquidoit $)+$ $\beta_{4}($ Concentração de Propriedadeit $)+\beta_{5}($ Graude Alavancagem Financeirait $)+w_{\text {it }}$

$\mathrm{Y}($ Composição do Endividamentoit $)=\beta_{0 i t}+\beta_{1}($ Governança Corporativait $)+$ $\beta_{2}$ (Tamanho da Empresait) $+\beta_{3}$ (Retorno sobre o Patrimônio Líquidoit $)+\beta_{4}($ Concentração de Proprieda$\left.\mathrm{de}_{\mathrm{it}}\right)+\beta_{5}($ Graude Alavancagem Financeirait $)+\varpi_{\mathrm{it}}$

Onde:

$\mathrm{Y}=$ variável dependente

$\beta=$ parâmetro associada a i-ésima empresa no t-ésimo ano ou ao intercepto

$\varpi=\varepsilon$ (efeito não observado de cada empresa) $+\mu$ (termo de erro)

$\mathrm{i}=$ representa as empresas

$\mathrm{t}=$ representa os anos

A normalidade dos dados é assumida pela Teoria do Limite Central. A análise gráfica dos resíduos padronizados versus os valores previstos indicou ausência de hoterocedasticidade. A suposição quanto à ausência de multicolinearidade foi analisada pela estatística VIF (Variance Inflation Factor). O procedimento empregado foi especificar uma regressão pelo método POLS (Pooled Ordinary Least Squared) e calcular a estatística VIF. Os resultados evidenciaram a ausência de multicolinearidade, visto que o VIF de todas as variáveis independentes, nos modelos estimados, ficou abaixo de 10 (dez).

\section{RESULTADOS DA PESQUISA}

A análise considerou, inicialmente, a compreensão, por meio de estatística descritiva, do comportamento das variáveis dependentes da pesquisa, a interpretação das variáveis independentes e a comparação destas com as demais variáveis empregadas no estudo (variáveis dependentes e de controle). Por fim, apresentam-se os resultados das análises de dados em painel, aplicadas visando atender ao objetivo do estudo.

\subsection{Endividamento das empresas de Energia Elétrica da B3}

Os dados de Endividamento Geral e Composição do Endividamento, obtidos por meio dos relatórios financeiros das empresas investigadas são apresentados na Tabela 1. 
Tabela 1 - Média Simples: Endividamento Geral e Composição do Endividamento - segmento de energia elétrica B3 2012 a 2017

\begin{tabular}{|c|c|c|c|c|c|}
\hline \multirow[b]{2}{*}{ Empresa } & \multicolumn{2}{|c|}{ Média } & \multirow[b]{2}{*}{ Empresa } & \multicolumn{2}{|c|}{ Média } \\
\hline & $\begin{array}{c}\text { Endivida- } \\
\text { mento Geral }\end{array}$ & $\begin{array}{l}\text { Composição do } \\
\text { Endividamento }\end{array}$ & & $\begin{array}{c}\text { Endivida- } \\
\text { mento Geral }\end{array}$ & $\begin{array}{l}\text { Composição do } \\
\text { Endividamento }\end{array}$ \\
\hline OMEGA GER (I) & $2 \%$ & $100 \%$ & COELCE (I) & $55 \%$ & $48 \%$ \\
\hline LIGHT S/A (I) & $2 \%$ & $99 \%$ & FGENERGIA (I) & $61 \%$ & $23 \%$ \\
\hline CELESC (I) & $2 \%$ & $70 \%$ & COSERN (I) & $61 \%$ & $42 \%$ \\
\hline UPTICK (I) & $6 \%$ & $100 \%$ & CPFL GERACAO (I) & $61 \%$ & $14 \%$ \\
\hline EQUATORIAL (I) & $9 \%$ & $90 \%$ & CEMAR (I) & $63 \%$ & $33 \%$ \\
\hline NEOENERGIA (I) & $10 \%$ & $45 \%$ & $\operatorname{COELBA}(\mathrm{I})$ & $63 \%$ & $41 \%$ \\
\hline CPFL ENERGIA (I) & $11 \%$ & $56 \%$ & AMPLA ENERG (I) & $63 \%$ & $35 \%$ \\
\hline AFLUENTE T (I) & $12 \%$ & $48 \%$ & ELEKTRO (I) & $64 \%$ & $41 \%$ \\
\hline ELETROPAR (I) & $13 \%$ & $30 \%$ & $\operatorname{EBE}(\mathrm{I})$ & $65 \%$ & $55 \%$ \\
\hline COPEL (I) & $14 \%$ & $32 \%$ & REDE ENERGIA (I) & $66 \%$ & $19 \%$ \\
\hline STATKRAFT (I) & $17 \%$ & $41 \%$ & CELPE (I) & $67 \%$ & $43 \%$ \\
\hline CEMIG (I) & $18 \%$ & $77 \%$ & CEMIG GT (I) & $67 \%$ & $37 \%$ \\
\hline ENERGIAS BR (I) & $20 \%$ & $44 \%$ & ENERSUL (I) & $68 \%$ & $35 \%$ \\
\hline ALUPAR (I) & $26 \%$ & $29 \%$ & AES SUL (I) & $69 \%$ & $48 \%$ \\
\hline TRAN PAULIST (I) & $28 \%$ & $27 \%$ & ENERGISA MT (I) & $70 \%$ & $41 \%$ \\
\hline EMAE (I) & $30 \%$ & $25 \%$ & TERMOPE (I) & $70 \%$ & $38 \%$ \\
\hline RENOVA (I) & $32 \%$ & $24 \%$ & CACHOEIRA (I) & $70 \%$ & $16 \%$ \\
\hline AES TIETE E (I) & $36 \%$ & $18 \%$ & STO ANTONIO (I) & $72 \%$ & $9 \%$ \\
\hline CEB (I) & $37 \%$ & $12 \%$ & ESCELSA (I) & $72 \%$ & $44 \%$ \\
\hline ENEVA (I) & $37 \%$ & $42 \%$ & LIGHT (I) & $78 \%$ & $36 \%$ \\
\hline CPFL RENOVAV (I) & $38 \%$ & $28 \%$ & ELETROPAULO (I) & $80 \%$ & $34 \%$ \\
\hline CESP (I) & $39 \%$ & $24 \%$ & CEMIG DIST (I) & $82 \%$ & $42 \%$ \\
\hline ENERGISA (I) & $44 \%$ & $20 \%$ & CELPA (I) & $82 \%$ & $35 \%$ \\
\hline CEEE-GT (I) & $45 \%$ & $29 \%$ & CPFL PIRATIN (I) & $88 \%$ & $42 \%$ \\
\hline ENGIE BRASIL (I) & $48 \%$ & $33 \%$ & PAUL F LUZ (I) & $88 \%$ & $41 \%$ \\
\hline ELETROBRAS (I) & $49 \%$ & $15 \%$ & PROMAN (I) & $95 \%$ & $18 \%$ \\
\hline TAESA (I) & $49 \%$ & $20 \%$ & TERM. PE III (I) & $101 \%$ & $59 \%$ \\
\hline ITAPEBI (I) & $53 \%$ & $49 \%$ & CEEE-D (I) & $109 \%$ & $42 \%$ \\
\hline GER PARANAP (I) & $53 \%$ & $39 \%$ & CELGPAR (I) & $535 \%$ & $17 \%$ \\
\hline
\end{tabular}

Fonte: Dados da pesquisa (2020).

A partir destes dados obteve-se a estatística descritiva das variáveis dependentes, conforme a Tabela 2 . 
Tabela 2 - Estatística Descritiva: Endividamento Geral e Composição do Endividamento - segmento de energia elétrica B3 - 2012 a 2017

\begin{tabular}{c|c|c}
\hline Variável & Endividamento Geral & Composição do Endividamento \\
\hline Média & $58 \%$ & $40 \%$ \\
\hline Mediana & $54 \%$ & $38 \%$ \\
\hline Maior Valor & $535 \%$ & $100 \%$ \\
\hline Menor Valor & $2 \%$ & $9 \%$ \\
\hline Amplitude & $533 \%$ & $91 \%$ \\
\hline Desvio Padrão & $69 \%$ & $21 \%$ \\
\hline
\end{tabular}

Fonte: Elaborado pelos autores (2020).

Quanto aos índices de Endividamento Geral e Composição do Endividamento, as empresas apresentaram médias simples de $58 \%$ e $40 \%$ respectivamente. Destaca-se a amplitude das amostras.

Considerando a média simples de Endividamento Geral, 28 empresas registraram valores acima da média do setor e outras 30 empresas apresentaram valores abaixo da média. Destaca-se que a média desta variável é majorada em 8 pontos percentuais devido ao índice de $535 \%$ da empresa CELGPAR. Salienta-se que apenas 3 empresas apresentaram endividamento superior a $100 \%$.

A variável Composição do Endividamento apresentou média simples de $40 \%$. Para o setor, o valor do endividamento de curto prazo é inferior ao endividamento de longo prazo. Entre as empresas, 27 empresas apresentaram índice superior à média do setor, e 31 empresas contabilizaram índice inferiores a essa média. Destacam-se as empresas UPTICK e OMEGA GER, as quais apresentaram índice de $100 \%$, ou seja, todas as obrigações da empresa são de curto prazo.

As empresas TERM. PE III; CELGPAR e CEEE-D registraram média negativa quanto ao Patrimônio Líquido, o que resultou na Participação de Capital de Terceiros negativos. A média simples resultou em um índice de $248 \%$, o que evidencia que as empresas do setor são financiadas majoritariamente pelo Capital de Terceiros. Entre as empresas com financiamento de capital próprio, destacam-se OMEGA GER, LIGHT S/A e CELESC, cujo patrimônio líquido representa 98\% do total do passivo destas.

Os dados apresentados demonstram a heterogeneidade da composição da estrutura de capital e da estratégia de endividamento das empresas do setor estudado.

\subsection{Concentração de Capital e Governança Corporativa}

A análise descritiva das variáveis indicou que a média simples da Concentração de Capital foi de $75 \%$, caracterizando o setor como altamente concentrado. As empresas que não pertencem aos níveis de Governança Corporativa da B3 apresentaram média de 89\% e as inseridas nos níveis de GC da B3 registraram média de Concentração de Capital de 57\%. Sant'Ana et al. (2016) identificaram média de $54 \%$ na concentração de propriedade em posse do acionista majoritário nas empresas do setor elétrico inseridas nos níveis de Governança Corporativa da bolsa de valores brasileira.

Das 58 empresas analisadas, 50 apresentaram concentração de propriedade, em que o acionista majoritário é detentor de $50 \%$ ou mais das ações ordinárias (com direito a voto). Empresas com capital acionário pulverizado, nas quais o acionista majoritário detém a posse de menos de $50 \%$ das ações ordinárias, somaram 8 companhias.

Elaborou-se uma tabela cruzada com o emprego das variáveis Concentração de Capital e Governança Corporativa, conforme apresentado na Tabela 3. 
Tabela 3 - Classificação das empresas quanto a Estrutura de Propriedade e a Governança Corporativa - segmento de energia elétrica B3 - 2012 a 2017

\begin{tabular}{|c|c|c|c|}
\hline \multirow{2}{*}{$\begin{array}{l}\text { Estrutura de } \\
\text { Propriedade }\end{array}$} & \multicolumn{2}{|c|}{ Governança Corporativa } & \multirow{2}{*}{$\begin{array}{c}\text { Total } \\
\text { da } \\
\text { linha }\end{array}$} \\
\hline & Com Governança & Sem Governança & \\
\hline Concentrado & $\begin{array}{l}18 \text { empresas: AES TIETE E (I); } \\
\text { ALUPAR (I); CACHOEIRA (I); } \\
\text { CEEE-D (I); CEEE-GT (I); CELESC } \\
\text { (I); CEMAR (I); CEMIG (I); COPEL } \\
\text { (I); CPFL ENERGIA (I); CPFL } \\
\text { RENOVAV (I); ELETROBRAS (I); } \\
\text { ELETROPAULO (I); ENERGISA } \\
\text { (I); ENGIE BRASIL (I); OMEGA } \\
\text { GER (I); TRAN PAULIST (I); } \\
\text { UPTICK (I) }\end{array}$ & $\begin{array}{l}32 \text { empresas: AES SUL (I); AFLUENTE T (I); } \\
\text { AMPLA ENERG (I); CEB (I); CELGPAR (I); } \\
\text { CELPA (I); CELPE (I); CEMIG DIST (I); CEMIG } \\
\text { GT (I); COELBA (I); COELCE (I); COSERN (I); } \\
\text { CPFL GERACAO (I); CPFL PIRATIN (I); EBE (I); } \\
\text { ELEKTRO (I); ELETROPAR (I); EMAE (I); } \\
\text { ENERGISA MT (I); ENERSUL (I); ESCELSA (I); } \\
\text { FGENERGIA (I); GER PARANAP (I); ITAPEBI } \\
\text { (I); LIGHT (I); NEOENERGIA (I); PAUL F LUZ } \\
\text { (I); REDE ENERGIA (I); STATKRAFT (I); STO } \\
\text { ANTONIO (I); TERM. PE III (I); TERMOPE (I) }\end{array}$ & 50 \\
\hline Pulverizado & $\begin{array}{l}08 \text { empresas: CESP (I); ENERGIAS } \\
\text { BR (I); ENEVA (I); EQUATORIAL } \\
\text { (I); LIGHT S/A (I); PROMAN (I); } \\
\text { RENOVA (I); TAESA (I) }\end{array}$ & & 08 \\
\hline Total da coluna & 26 & 32 & \\
\hline
\end{tabular}

Fonte: Dados da pesquisa (2020).

Formaram-se quatro categorias para o desenvolvimento da análise, contudo, houve classificação das empresas em apenas três delas. Não houve empresas identificadas com estrutura de capital pulverizada e sem nível de governança corporativa.

Foram classificadas oito empresas na categoria de empresas com a Estrutura de Propriedade Pulverizada e que possuem Governança Corporativa.

São 50 empresas que possuem concentração de propriedade classificada como Concentrada. Destas, 18 apresentam Governança Corporativa e 32 foram classificadas na categoria, sem governança corporativa.

Salienta-se que a partir de uma análise geral, 26 empresas apresentaram Governança Corporativa e 32 não se encontram em nenhum nível de Governança Corporativa, estando estas também no grupo de empresas Estrutura de Propriedade Concentrado.

A Tabela 4 evidencia os grupos, formados a partir das variáveis independentes, que obtiveram resultados mais relevantes quanto às variáveis dependentes e variáveis de controle utilizadas na pesquisa. Para a construção da tabela calculou-se a média simples dos índices nos anos analisados para cada um dos grupos apresentados na Tabela 3. Após isso, realizou-se a classificação evidenciada na Tabela 4, de quais grupos apresentaram maiores e menores índices.

Tabela 4 - Desempenho dos grupos quanto as variáveis dependentes e variáveis de controle - segmento de energia elétrica B3 - 2012 a 2017

\begin{tabular}{ccc}
\hline Variável & Maior índice & Menor índice \\
\hline Tamanho da empresa & Concentrado e com Governança & Concentrado sem Governança \\
Retorno sobre o Patrimônio Líquido & Concentrado sem Governança & Pulverizado e com Governança \\
Grau de Alavancagem Financeira & Concentrado sem Governança & Concentrado e com Governança \\
Endividamento Geral & Concentrado sem Governança & Pulverizado e com Governança \\
Composição do Endividamento & Pulverizado e com Governança & Concentrado sem Governança \\
\hline
\end{tabular}

Fonte: Dados da pesquisa (2020). 
O grupo de empresas Concentrado e com Governança apresentou maior montante de ativos totais em relação aos outros grupos. Isso demonstra que, no setor, as maiores empresas têm Concentração de Propriedade e estão inseridos em algum dos níveis de GC da B3. As empresas do grupo Concentrado e sem Governança apresentaram o menor índice quanto ao tamanho da empresa, em contraponto a isso, registraram os maiores índices de Retorno Sobre o Patrimônio Líquido, Grau de Alavancagem Financeira e de Endividamento Geral. Os índices desse grupo vão de encontro à teoria do Pecking Order, pela qual as empresas utilizam-se do capital de terceiros para alavancar as aplicações de recursos e remunerar o capital próprio.

Quanto à Composição do Endividamento, todos os grupos apresentaram o montante de passivo não circulante superior ao passivo circulante, isto foi mais acentuado no grupo Concentrado sem Governança. A maioria das empresas registrou índice de Participação de Capital de Terceiros superior a 1, ou seja, são majoritariamente financiadas pelo Capital de Terceiros. O grupo Pulverizado e com Governança foi o que apresentou o maior número de empresas com esta característica.

\subsection{Influência da Concentração de Propriedade e da Governança Corporativa no Endividamento}

Nesta seção são apresentadas as análises de dados em painel, com o objetivo de evidenciar o poder explicativo da Concentração de Propriedade e da Governança Corporativa sobre os níveis de Endividamento das companhias do segmento de energia elétrica da B3, entre os exercícios de 2012 a 2017.

O primeiro passo foi determinar qual método deve-se empregar nas análises. Esse procedimento é explicado na metodologia da presente pesquisa. Os resultados são apresentados na Tabela 5.

Tabela 5 - Teste de dados em painel

\begin{tabular}{ccc}
\hline Teste & Endividamento Geral & Composição do Endividamento \\
\hline Breusch-Pagan: & 0,000 & 0,000 \\
Hausman: & 0,068 & 0,772 \\
Efeitos & Aleatórios & Aleatórios \\
\hline
\end{tabular}

Fonte: Dados da pesquisa (2020).

A partir dos resultados apresentados na Tabela 5, concluiu-se que é mais consistente para a amostra em estudo a utilização do modelo de efeitos aleatórios para as regressões das variáveis dependentes: Endividamento Geral e Composição do Endividamento. As Tabelas 6 e 7 apresentam os resultados das regressões.

Na Tabela 6 consta o resultado da regressão considerando como variável dependente o Endividamento Geral.

Tabela 6 - Variável dependente: Endividamento Geral - 2012 a 2017

\begin{tabular}{cccccc}
\hline Variáveis & Coeficientes & Erro Padrão & Razão-t & P-valor & Sig. \\
\hline Constante & $-6,47090$ & 1,97409 & $-3,278$ & 0,0010 & $* * *$ \\
Governança Corporativa & $-0,52394$ & 0,31118 & $-1,684$ & 0,0922 & $*$ \\
Tamanho da Empresa & 0,18250 & 0,07482 & 2,439 & 0,0147 & $* *$ \\
Retorno sobre o Patrimônio Líquido & 0,14629 & 0,05168 & 2,831 & 0,0046 & $* * *$ \\
Concentração de Propriedade & 0,78139 & 0,35927 & 2,175 & 0,0296 & $* *$ \\
Grau de Alavancagem Financeira & $-0,07496$ & 0,06606 & $-1,135$ & 0,2565 & \\
\hline
\end{tabular}

*Significativo ao nível de $10 \%$; **Significativo ao nível de 5\%; *** Significativo ao nível de 1\%

Fonte: Dados da pesquisa (2020). 
Ambas as variáveis independentes do modelo apresentam valores com algum grau de significância estatística.

A variável Governança Corporativa $(\operatorname{sig}=0,0922 ; p<0,10)$ mostrou-se significante e a relação foi negativa quanto ao Endividamento Geral, evidenciando que as empresas que estão inseridas em algum nível de Governança Corporativa da B3 são menos endividadas. Estes resultados corroboram a hipótese $02(\mathrm{H} 2)$ do estudo. Este resultado também é evidenciado em Pinheiro et al. (2017) que apresentaram relação negativa entre governança corporativa e endividamento. Os resultados evidenciam o que preceitua a Teoria Pecking Order para o caso das empresas de energia elétrica listadas na B3. Mendonça, Martins e Terra (2019) também identificaram resultados aderentes a Teoria Pecking Order.

Silveira (2004) indica que há uma relação direta entre a governança corporativa e a estrutura de capital. Considerando que a estrutura de capital de empresas com um alto índice de investimento realizado com o capital próprio, consequentemente apresentam um baixo índice de endividamento, tendem a ter maior liquidez (Póvoa \& Nakamura, 2015).

A variável Concentração de Propriedade ( $\operatorname{sig}=0,0296 ; \mathrm{p}<0,05)$ influenciou positivamente $\mathrm{o}$ Endividamento Geral, indicando que empresas com mais elevada Concentração de Propriedade são mais endividadas, corroborando com a hipótese 01 (H1) do estudo.

Estes resultados estão de acordo com outros estudos que apresentam a redução dos conflitos de agência por meio da concentração de propriedade como influenciador no acesso a financiamento externo (Crisóstomo \& Pinheiro, 2015; Goergen \& Renneboog, 2001)

A existência do Capital de Terceiros resulta na Alavancagem Financeira da empresa (Meyers, 1983). Entretanto essa alavancagem apenas será relevante se o retorno sobre o capital investido for superior ao custo de aquisição deste capital. Contudo, mesmo com a relação direta entre os fatores, a variável de controle Grau de Alavancagem Financeira não apresentou significância estatística no modelo estimado. Deste modo, pode-se inferir que, apesar da concentração de propriedade influenciar o endividamento geral das empresas pesquisadas, não é possível estabelecer o grau de endividamento a partir da alavancagem financeira.

Entre as demais variáveis de controle, o Retorno sobre o Patrimônio Líquido mostrou-se muito significativa em relação ao Endividamento Geral (sig=0,0046; $\mathrm{p}<0,01$ ). Esse resultado mostra que empresas do setor elétrico da B3 com altos índices de Retorno sobre o Patrimônio Líquido são mais endividadas, corroborando o fato de que o financiamento do Ativo pelo Capital de Terceiros remunera o Capital Próprio da empresa.

O Tamanho da Empresa ( $\operatorname{sig}=0,0147 ; \mathrm{p}<0,05)$ também foi estatisticamente significante para com o Endividamento Geral. Assim, empresas com o montante de ativo total mais elevado são as mais endividadas, aspecto que pode ser justificado pela facilidade de aquisição de créditos e financiamentos para suas atividades. Resultado semelhante é observado em Crisóstomo e Pinheiro (2015).

Considerando como variável dependente a Composição do Endividamento o resultado é apresentado na Tabela 7. 
Tabela 7 - Variável dependente: Composição do Endividamento - 2012 a 2017

\begin{tabular}{|c|c|c|c|c|c|}
\hline Variáveis & Coeficientes & Erro Padrão & Razão-t & P-valor & Sig. \\
\hline Constante & $-0,13546$ & 1,67634 & $-0,080$ & 0,935 & \\
\hline Governança Corporativa & $-0,07218$ & 0,25454 & $-0,283$ & 0,776 & \\
\hline Tamanho da Empresa & 0,01014 & 0,06772 & 0,149 & 0,881 & \\
\hline Retorno sobre o Patrimônio Líquido & 0,15975 & 0,06804 & 2,348 & 0,018 & $* *$ \\
\hline Concentração de Propriedade & $-0,20079$ & 0,29403 & $-0,682$ & 0,494 & \\
\hline Grau de Alavancagem Financeira & 0,03282 & 0,08481 & 0,387 & 0,698 & \\
\hline
\end{tabular}

*Significativo ao nível de $10 \%$; **Significativo ao nível de 5\%; *** Significativo ao nível de 1\%

Fonte: Dados da pesquisa (2020).

Em relação à Composição do Endividamento, as variáveis independentes Governança Corporativa (sig=0,7767; p>0,10) e Concentração de Propriedade $(\operatorname{sig}=0,4947 ; \mathrm{p}>0,10)$ não apresentaram valores com significância estatística. Deste modo, observa-se que não é possível inferir a influência destas na forma em que o Capital de Terceiros é adquirido.

Apesar de estudos empíricos verificarem a influência existente sobre a composição do endividamento (dívidas de curto e longo prazo), como Crisóstomo e Pinheiro (2015) que comprovaram o efeito da concentração de propriedade, e de Pinheiro et al. (2017) que evidenciaram a influência da governança corporativa sobre o endividamento, no presente estudo, com a amostra estudada, não foi possível corroborar os resultados dos estudos mencionados.

Apenas a variável de controle Retorno sobre o Patrimônio Líquido $(\operatorname{sig}=0,0189 ; \mathrm{p}<0,05)$ mostrou-se significante estatisticamente e positiva. Com isso, as empresas analisadas que registraram altos índices de Retorno sobre o Patrimônio Líquido têm seu Capital de Terceiros composto majoritariamente pelo Passivo Circulante.

As variáveis de controle Tamanho da Empresa (sig=0,881; $>>0,10)$ e Grau de Alavancagem Financeira (sig=0,6988; p>0,10) também não apresentaram significância estatística na Composição do Endividamento das empresas do segmento de energia elétrica da B3, entre 2012 e 2017.

\section{CONSIDERAÇÕES FINAIS}

O setor de energia elétrica brasileiro demonstrou alta concentração acionária em favor de um acionista majoritário, no período de 2012 a 2017. Das 58 empresas analisadas deste segmento da B3, 50 companhias apresentaram Concentração de Propriedade. Esses dados reafirmam as pesquisas de Silveira (2002 e 2004) e Okimura et al. (2007), que identificaram este mesmo comportamento no setor. Quanto à governança corporativa, 26 empresas estão inseridas em um dos níveis de governança da B3.

O setor apresentou um nível de endividamento médio nos anos analisados de $58 \%$. A média simples de composição do endividamento evidenciou que as companhias que integram o segmento de energia elétrica da B3 têm seus endividamentos compostos por $40 \%$ de passivos de curto prazo e $60 \%$ em passivos de longo prazo.

Quanto à relevância da Concentração de Propriedade e da Governança Corporativa sobre os níveis de endividamento, as variáveis investigadas demonstraram exercer influência no Endividamento Geral.

A governança corporativa exerceu influência negativa na estrutura de capital, especificamente para este estudo, na relação entre capital próprio e de terceiros. O maior controle exercido sobre a gestão estabelece critérios que impactam na busca por decisões de menor risco. Considerando a ordem de endividamento proposto pela teoria Pecking Order, a primeira fonte de financiamento das atividades empresariais são os recursos próprios. Assim, a empresa estaria menos exposta a riscos. Deste modo, os resultados encontrados que estabelecem a relação negativa 
entre a governança corporativa e o endividamento geral demonstram que, quando maior foi o indicador de governança, houve a propensão de menor endividamento das empresas do segmento de energia elétrica da B3, entre os anos de 2012 a 2017.

Por outro lado, a concentração de propriedade oferece ao acionista majoritário maior poder de agência e implica na busca pelo aumento da remuneração do capital próprio. Este aumento é obtido pela alavancagem financeira. A aquisição de dívidas é alternativa à emissão de ações que pode resultar em perda de poder (controle acionário) para empresas com alta concentração de propriedade. Os resultados identificados para o segmento de energia elétrica da B3, entre 2012 a 2017, demonstraram que o maior controle acionário destas empresas determinou também maior índice de endividamento geral.

Contudo, não foi possível evidenciar a relação das variáveis investigadas com a composição do endividamento. Ambas não foram significantes em relação à Composição do Endividamento, junto às empresas de energia elétrica que negociam suas ações na B3 no período analisado.

As variáveis Tamanho da Empresa e o Retorno sobre o PL influenciaram o Endividamento Geral, e quanto à Composição do Endividamento, somente o Retorno sobre o PL se mostrou influente.

Estudos como os de Klapper e Love (2004), Mapurunga et al. (2015) e Brandão e Crisóstomo (2015) revelaram que o endividamento pode levar a empresa a modificar ou alterar seus padrões de governança pela pressão exercida por credores, com a finalidade de reduzir o risco de não obterem retorno de seus investimentos.

Por outro lado, o estudo realizado por Okimura (2003) se contrapõe ao estudo empírico de Demsetz e Lehn (1985), os quais argumentam que a relação entre a concentração de propriedade e desempenho das empresas não existe. Assim, fatores como nível de ativos e resultados históricos têm influência sobre a concentração de propriedade e não os resultados financeiros.

Ressalta-se que os resultados da presente pesquisa limitam-se as empresas que integraram o segmento de energia elétrica da B3 no período avaliado, 2012 a 2017, bem como as técnicas estatísticas utilizadas na análise da amostra.

Como sugestões de estudos futuros destaca-se a repetição da aplicação do modelo para um recorte temporal atual, estabelecendo a comparabilidade com os resultados alcançados. Ainda sugere-se a investigação da influência das variáreis independentes utilizadas neste estudo (governança corporativa e concentração de propriedade) nos indicadores individuais de dívidas de curto prazo e dívidas de longo prazo, em vez de estabelecer a relação com a composição do endividamento.

\section{REFERÊNCIAS}

Andrade, A; \& Rossetti, J. P. (2004). Governança corporativa: fundamentos, desenvolvimento e tendências. São Paulo: Atlas.

Aneel. (2018). Disponível em: <http://www.aneel.gov.br/>. Acesso em: 23 nov.

B3. (2018). Disponível em: <http://www.b3.com.br/pt_br/>. Acesso em: 23 nov.

Baker, M., \& Wurgler, J. (2002). Market timing and capital structure. The Journal of Finance, 57(1), 132. DOI: https://doi.org/10.1111/1540-6261.00414

Bastos, D. D., \& Nakamura, W. T. (2009). Determinantes da estrutura de capital das companhias abertas no Brasil, México e Chile no período 2001-2006. Revista Contabilidade \& Finanças, 20 (50), 75-94.

Brandão, I. F., Assunção, R. R., Ponte, V. M. R., \& Rebouças, P. (2013). Fatores determinantes do disclosure de guidance das companhias listadas na BM\&FBOVESPA. Revista Contemporânea de Contabilidade, 10(21), 87-114. 
Brandão, I. F. \& Crisóstomo, V. L. (2015). Concentração de propriedade e qualidade da governança da empresa brasileira. Revista Brasileira de Finanças, 13 (3), 438-469.

Crisóstomo, V. L., \& Pinheiro, B. (2015). Estrutura de Capital e Concentração de Propriedade da Empresa Brasileira (Capital Structure and Ownership Concentration of the Brazilian Firm). Revista de Finanças Aplicadas, 4., 1-30.

Demsetz, H., \& Lehn, K. (1985). The structure of corporate ownership: Causes and consequences. Journal of Political Economy, 93(6), 1155-1177.

Fávero, L. P., Belfiore, P., Silva, F. L. \& Chan, B. L. (2009). Análise de dados: Modelagem multivariada para tomada de decisões. Rio de Janeiro: Elsevier.

Fonseca, C. V. C., Silveira, R. L. F. \& Hiratuka, C. (2016). A relação entre a governança corporativa e a estrutura de capital das empresas brasileiras no período 2000-2013. Enfoque: Reflexão Contábil, 35(2), 35-52. DOI: https://doi.org/10.4025/enfoque.v35i2.29673

Goergen, M., \& Renneboog, L. (2001). Investment Policy, Internal Financing and Ownership Concentration in the UK. Journal of Corporate Finance, 7(3), 257-284.

Gomes, R. M. \& Pereira, A. A. (2014). Estrutura de Capital- Abordagem a teorias e variáveis explicativas. Review of Business and Legal Sciences, 25, 83-96.

Jensen, M. C. (1986). Agency costs of free cash flow, corporate finance, and takeovers. The American Economic Review, 76(2), 323-329.

Klapper, L. F. \& Love, I. (2004). Corporate governance, investor protection, and performance in emerging markets. Journal of Corporate Finance, 10, 703-728.

Liao, L. K., Mukherjee, T. \& Wang, W. (2015). Corporate governance and capital structure dynamics: an empirical study. The Journal of Financial Research, 38(2), 169-191. DOI: https://doi.org/10.1111/ jfir.12057

Mapurunga, P. V. R., Ponte, V. M. R., \& Oliveira, M. C. (2015). Determinantes das Práticas de Governança Corporativa: Um Estudo nas Empresas Registradas na CVM. Advances in Scientific and Applied Accounting, 8(3), 374-395.

Mazzioni, S., Prigol, V., Moura, G. D., \& Klann, R. C. (2015). Influência da governança corporativa e da estrutura de capital no gerenciamento de resultados. Revista Contemporânea de Contabilidade, 12(27), 61-86.

Mendonça, F. F., Martins, H. C., \& Terra, P. R. (2019). Estrutura de Capital e Mecanismos de Governança Externos à Firma: Uma Análise Multipaís. Revista de Administração Contemporânea, 23(6), 765-785.

Modigliani, F., \& Miller, M. H. (1958). The cost of capital, corporation finance and theory of investment. The American Economic Review, 48(3), 261-297.

Modigliani, F., \& Miller, M. H. (1963). Corporate Income Taxes and the Cost of Capital: A Correction. The American Economic Review, 53(3), 433-443.

Monte, P. A., Rezende, I. C. C., Teixeira, G. S., \& Besarria, C. N. (2010). Existe relação entre Governança Corporativa e volatilidade? Um estudo a partir da formação de carteiras. Contabilidade Vista \& Revista, 21(2), 15-44.

Myers, S. C. (1983). The Capital Structure Puzzle. The Journal of Finance, 34(3), 575-592.

Nakamura, W. T., Martin, D. M. L., Forte, D., Carvalho Filho, A. F. D., Costa, A. C. F. D., \& Amaral, A. C. D. (2007). Determinantes de estrutura de capital no mercado brasileiro: análise de regressão com painel de dados no período 1999-2003. Revista Contabilidade $\mathcal{E}$ Finanças, 18(44), 72-85.

Nardi, P. C. C. \& Nakao, S. H. (2008). Impacto da Entrada nos Níveis Diferenciados de Governança Corporativa sobre a Imagem Institucional das Empresas. Revista Contabilidade Vista e Revista, 19(2), 85-111. 
Niyama, J. K., Campos, E. S., Gonçalves, R. L., \& Campos, G. P. S. (2012). Reconhecimento, Mensuração e Evidenciação de Operações de Remunerações em Opções de Ações de Companhias Abertas Listadas nos Segmentos Especiais de Governança Corporativa pela BM\&FBOVESPA. Contabilidade Vista \& Revista, 23(3), 49-72.

Okimura, R. T. (2003). Estrutura de propriedade, governança corporativa, valor e desempenho das empresas no Brasil. 2003. Dissertação (Mestrado em Administração) - Faculdade de Economia, Administração e Contabilidade, Universidade de São Paulo, São Paulo.

Okimura, R. T., Silveira, A. D. M. D., \& Rocha, K. C. (2007). Estrutura de propriedade e desempenho corporativo no Brasil. RAC-Eletrônica, 1(1), 119-135.

Ortiz, A. S., Pilan, J., \& Carvalho, W. S. (2008). Estrutura de capital e risco: um estudo sobre a relação entre endividamento e risco para empresas de capital aberto. Revista de Estudos Universitários-REU, 34 (Edição Especial), 31-45.

Perobelli, F. F. C., \& Famá, R. (2003). Fatores determinantes da estrutura de capital para empresas latino-americanas. Revista de Administração Contemporânea, 7(1), 9-35.

Pinheiro, B. G., Vasconcelos, A. C., De Luca, M. M. M., \& Crisóstomo, V. L. (2017). Estrutura de capital e governança corporativa nas empresas listadas na BM\&FBovespa. Revista de Educação e Pesquisa em Contabilidade, 11(4), 451-466.

Pohlmann, M., Aguiar, A., Bertolucci, A., \& Martins, E. (2004). Impacto da especificidade de ativos nos custos de transação, na estrutura de capital e no valor da empresa. Revista Contabilidade $\mathcal{E}$ Finanças, 15 (Edição Especial), 24-40. DOI: https://doi.org/10.1590/S151970772004000400002

Póvoa, A. C. S., \& Nakamura, W. T. (2015). Relevância da estrutura de dívida para os determinantes da estrutura de capital: um estudo com dados em painel. Revista Contemporânea de Contabilidade, 12(25), 3-26.

Ross, S. A., Westerfield, R. W., Jaffe, J., \& Lamb, R. (2015). Administração financeira (10a.). Porto Alegre: AMGH Editora.

Sant'Ana, N. L. D. S., Medeiros, N. C. D. D., Silva, S. A. D. L., Menezes, J. P. C. B., \& Chain, C. P. (2016). Concentração de propriedade e desempenho: um estudo nas empresas brasileiras de capital aberto do setor de energia elétrica. Gestão \& Produção, 23(4), 718-732.

Silva, K. L., Oliveira, M. C., Mendes De, M. M., \& Araújo, O. C. (2009). A Implementação dos Controles Internos e do Comitê de Auditoria Segundo a Lei SOX: o Caso Petrobras. Contabilidade Vista \& Revista, 20(3), 39-63.

Silveira, A. M. (2002). Governança corporativa, desempenho e valor da empresa no Brasil. Dissertação (Mestrado em Administração) - Faculdade de Economia, Administração e Contabilidade, Universidade de São Paulo, São Paulo. DOI: https://doi.org/10.11606/D.12.2002.tde04122002-102056.

Silveira, A. M. (2004). Governança corporativa e estrutura de propriedade: determinantes e relação com o desempenho das empresas no Brasil. Tese (Doutorado em Administração) - Faculdade de Economia, Administração e Contabilidade, Universidade de São Paulo, São Paulo.

Silveira, A. D. M. D., Perobelli, F. F. C., \& Barros, L. A. B. D. C. (2008). Governança corporativa e os determinantes da estrutura de capital: evidências empíricas no Brasil. Revista de Administração Contemporânea, 12(3), 763-788.

Tolmasquim, M. T., Guerreiro, A., \& Gorini, R. (2007). Matriz energética brasileira: uma prospectiva. Novos Estudos - CEBRAP, 79, 47-69.

Valadares, S. M. (1998). Três ensaios sobre mercado por controle no Brasil. Pontifícia Universidade Católica do Rio de Janeiro. 
Vieira, K. M., Velasquez, M. D. P., Losekann, V. L., \& Ceretta, P. S. (2011). A influência da governança corporativa no desempenho e na estrutura de capital das empresas listadas na Bovespa. Revista Universo Contábil, 7(1), 49-67. 